\title{
The Effect of Oral Date Syrup on Severity of Labor Pain in Nulliparous
}

\author{
Simin Taavoni ${ }^{1,2,3}$, Leila Fathi ${ }^{4,}{ }^{*}$, Neda Nazem Ekbatani ${ }^{5}$ and Hamid Haghani ${ }^{6}$ \\ ${ }^{1}$ Research Institute for Islamic and Complementary Medicine, Iran University of Medical Sciences, Tehran, Iran \\ ${ }^{2}$ Department of Midwifery, School of Nursing and Midwifery, Iran University of Medical Sciences, Tehran, Iran \\ ${ }^{3}$ School of Medicine, Tehran University of Medical Sciences, Tehran, Iran \\ ${ }^{4}$ Department of Midwifery, School of Nursing and Midwifery, Lorestan University of Medical Sciences, Khorramabad, Iran \\ ${ }^{5}$ School of Nursing and Midwifery, Tehran University of Medical Sciences, Tehran, Iran \\ ${ }^{6}$ Department of Biostatistics, School of Nursing and Midwifery, Iran University of Medical Sciences, Tehran, Iran \\ "Corresponding author: MSc in Midwifery, School of Nursing and Midwifery, Lorestan University of Medical Sciences, Kamalvand Campus, Khorramabd, Iran. Tel: \\ +98-9163677217, Email: midwifer.fathi@gmail.com
}

Received 2018 April 08; Revised 2018 September 10; Accepted 2018 September 18.

\begin{abstract}
Background: Labor is painful phenomenon and management of labor pain has particular importance. For labor pain management pharmacological and non-pharmacological methods are used, but today there is a tendency for using alternative and complementary medicine. Consumption of nutrients and hydration is also one of the ways of pain management during labor.

Objectives: This study aimed to investigate the effect of oral administration of palm syrup on the labor pain of nulliparous women. Methods: This study was a randomized clinical trial. In this study, 80 healthy nulliparous women were enrolled and randomly divided into two groups of the control group and palm syrup. The intervention group received palm syrup while the control group received only water routinely. Interventions in both groups continued during the active phase until the transitional phase. Data were collected by four main parts of the demographic questionnaire, controls carried out in labor, recording the fluid intake rate, and recording the pain using a ruler as $10-0 \mathrm{~cm}$.

Results: The mean pain intensity was significantly lower in intervention group of the palm syrup than the control group.

Conclusions: The use of palm syrup had a significant impact on labor pain. Given the importance of evidence-based research and its usage in practice, conducting more studies are necessary in these areas.
\end{abstract}

Keywords: Complementary and Alternative Therapies, Pain Management, Labor, First Stage, Labor Pain, Nulliparous

\section{Background}

Labor is a painful physiological process in which regular uterine contractions is associated with effacement and dilation of the cervix leading to the expulsion of the fetus from the uterus (1). Labor pain is normal and isn't caused by disease, trauma and tissue damage (2). Labor pain leads to activation of the sympathetic nervous system and lack of control increases over the levels of catecholamines, resulting in increased cardiac output, blood pressure, (3) reduced blood supply to the uterus (4) and elongation of the Lederman et al. (5). In addition, lack of labor pain control has effects on the reduction of mental self-control of mother during labor and is the key factor in the development of birth trauma and traumatized mothers and even in the postpartum period and also play a role in the advancement of the symptoms of women's stress (6). Therefore, control and management of labor pain is one of the most important care and support priorities of health care system (7). However, controlling labor pain and its man- agement during labor is still one of the most important challenges of pregnant women and the health care system. Today, in order to reduce pain and make the delivery pleasant, pharmaceutical and non-pharmaceutical methods are used (8). Pharmaceutical methods of pain reduction are always associated with maternal and fetal complications (9). It is the desire to use non-invasive methods including alternative and complementary methods (10). The results of various studies report variety of nonpharmacological pain reliever methods among which the use of relaxation, acupuncture and acupressure, hydrotherapy, cold heat therapy, herbal medicine (11), music therapy, aromatherapy, electrical nerve stimulation (12), labor ball (13), massage, reflexology (14), intradermal injections of sterile liquid, hypnotism (15) can be mentioned. Also in recent decades, in order to avoid hard labor, mothers need for energy and the need to eat and drink during the labor has been specially considered (16). Another way of reducing pain can be the consumption of nutrients and fluid intake which may be effective for pain relieve (17). In this regard, 
date palm can be mentioned as a nutrient.

Date palm with scientific name Phoenix dactiliferia and with a consumption history of 7,000 years is a plant with a stable high nutritional value (18). Among the properties of date palm, adjusting the properties of the menstrual cycle and reducing menstrual pain (19), anti-inflammatory, immune booster, anti-virus and anti-cancer (20) can be noted. A number of studied have also been conducted on the benefits of date palm including antioxidant effect, protecting the nervous system (21), protecting the digestive system and anti-diarrhea (22), treatment of the liver (23), antibacterial (24), increased libido (25), reducing bleeding after childbirth (26) and reducing the duration of labor (27). In verses 23 - 26 of Surah Maryam, it was also mentioned that Holy Maryam was recommended to eat date fruits at the birth of Christ (Holy Quran, Surah Maryam [19:2326]). Despite the numerous advantages of date palm, experimental studies conducted in connection with the analgesic effect of date palm show contradictory results; however pain reduction has been observed in mice consuming date fruits (28), while similar studies in mice showed that although pain threshold was somewhat lower, the difference was not statistically significant (29). However, extensive computer searches in connection with the relationship between the effects of date fruits on the reduction of labor pain was achieved. According to the limited and contradictory results of the mentioned studies, the researchers decided to investigate the analgesic effect of date palm syrup on the reduction of labor pain.

\section{Methods}

In this randomized clinical trial, 80 volunteer nulliparous women were eligible for inclusion (aged between 38 - 42 pregnancy weeks, cephalic presentation, the physical and mental health, no history of infertility, having a normal delivery conditions, opening of the cervix at a rate of $7.4 \mathrm{~cm}$, having no history of allergy to date palm syrup) at the active phase of labor with cervical dilatation of 4 $7 \mathrm{~cm}$ were randomly divided into control and intervention with palm syrup group. Data collection in this study was divided into four main sections including demographic characteristics (age, education, employment status, willingness to current pregnancy, gestational age, abortion), recoding the controls in labor (during contractions, length contractions and fetal heart rate) and vaginal examinations (dilation, effacement, positions, stations, and the water bags), record fluid intake (date syrup or water) and recording the pain intensity using a ruler of $0-10 \mathrm{~cm}$.

In this study, samples were randomly assigned to the palm syrup group (card No. 1) or placebo group (card No.
2). The first person who chose a card was randomly selected, and then placed in each of the two groups and the next person was placed in the other group. For example, if the first person chose the number two, he would be placed in the control group, and as a result, the next person would be in the palm syrup group, and again for the third one, both cards were submitted for selection. Also, none of the samples were aware of the nature of the numbers 1 and 2 cards, and after the selection of the card, the process of doing research was explained to them. The random allocation of samples was done by the researcher, but in order to prevent bias in the research, the researcher's colleague (who was not aware of the nature of each person in each of the two groups) was used to record the severity of pain.

Throughout the research process, the researcher conducted the control and registration of all examinations personally in the intervention group and the control group, so that the length and intervals of uterine contractions and fetal heart rate at baseline and also every $30 \mathrm{~min}$ and dilatation, effacement, station, the membrane at baseline and then every 2 hours, through vaginal examination were examined in accordance with the protocols, and rebound support was continued by the researcher, despite the completion of the research where dilatation was $8 \mathrm{~cm}$ and until the end of the labor stage, because it was not morally correct to curtail the support. In order to prevent bias during the study, pain intensity was recorded by a researcher using a pain ruler, such that at the beginning of the study, and then for every 30 minutes, a research fellow with the $0-10 \mathrm{~cm}$ ruler recorded pain intensity and after the training of samples, they were asked questions regarding pain intensity.

In order to prepare the palm syrup, 6 palm crop products were mixed after extracting the core in a blender, mix thoroughly to ensure complete smoothness and it was prepared as a pulp free syrup mixed in $150 \mathrm{~mL}$ of water. Regarding the possibility of glucose effect on pain intensity, in this study, in the control group, only non-sweet liquids, including water or sugar-free tea, were presented as requested by the study samples.

Liquid preparation was recorded at baseline and then for every 30 minutes to 60 minutes and the volume of fluid intake was also recorded.

Regarding blindness in the present study, it should be noted that taking care of one to one care can affect the severity of pain, so all the care and controls performed during the labor cycle include vaginal examinations, examination of contractions, check fetal heart rate were taken by the researcher himself. Incidentally, this is strength point of the present research. Also, in order to blindness and preventing bias, the research team was used the fellow researchers to record the pain intensity. In fact, the fellow 
researchers, without any knowledge of the nature of the subjects studied in which of the two groups, recorded the severity of pain, on the other hand, the Statistician was also blinded until the analysis was completed.

For data analysis, SPSS V. 16 software was used. In order to identify demographic characteristics, analysis of variance, chi-square and Fisher's exact test, and for determination of vaginal examinations, Kruskal-Wallis and chisquare tests, and also to compare the pain intensity, analysis of variance, Kruskal-Wallis test, and also due to the special nature of labor pain for more assessment, the Scheffe test, Mann-Whitney test, and repeated measures ANOVA and Bonferroni and Greenhouse-Geisser corrections were used.

This study was approved by the Ethics Committee of Tehran University of Medical Sciences (TUMS) with code: 132686-9111373029.

\section{Results}

In this study, 80 nulliparous women who met the criteria of the study and had no significant difference in terms of the demographic characteristics and specifications of homogeneous vaginal examinations at baseline were enrolled (Table 1). Non-homology of the pain in the control and palm syrup groups at baseline could affect the interpretation of results as a confounding variable. The severity of pain was determined before the intervention and the result of ANOVA showed that the average pain score obtained in both groups at baseline were not significantly different and both groups were at the same level in terms of pain at baseline $(\mathrm{P}=0.76)$. However, a comparison of pain in the intervention group and the control group at 30-150 min after entering the study showed that the severity of pain after 30 min didn't reduce but in 60 - 150 min, average pain intensity was significantly reduced in the intervention group (Table 2).

\begin{tabular}{|c|c|c|c|}
\hline Characteristics & Palm Syrup & Control & P Value \\
\hline Age, $y$ & $25.40 \pm 4.51$ & $24.90 \pm 4.21$ & 0.71 \\
\hline Education, diploma & $19(47.5)$ & $15(37.5)$ & 0.90 \\
\hline Occupation, housewife & $37(92.5)$ & $36(90)$ & 1.00 \\
\hline Tend to pregnancy, demands ${ }^{b}$ & $38(95)$ & $39(97.5)$ & 1.00 \\
\hline Gestational age, wk & $39.64 \pm 0.99$ & $39.65 \pm 1.00$ & 0.97 \\
\hline Dilatation, $\mathrm{cm}$ & $4.97 \pm 0.80$ & $5.00 \pm 0.85$ & 0.95 \\
\hline
\end{tabular}

\section{Discussion}

This study was conducted to evaluate the analgesic effects of date palm syrup on the intensity of labor pain of nulliparous women. The findings of this study showed that consumption of date palm syrup significantly reduces labor pain. It should be noted that through the vast computer resources search and based on evidence, no study has been conducted to date to investigate the effect of date palm syrup on the severity of labor pain, but similar studies have been conducted. In a study conducted by Ergol et al. (17), the aim was to evaluate the effect of oral liquid nutrition on labor progress and labor pain. Labor pain was measured using the visual analogue scale (VAS) and there was no significant difference in the total length of active phase in the two groups and nutrient and fluid intake during labor did not reduced the pain. However, in this study, in the first 30 min after intervention, there was no reduction in labor pain; but within 60 - $150 \mathrm{~min}$, labor pain was reduced significantly in the intervention group. Studies of Hekmatzadeh et al. (30), showed that following oral administration of brewed sure eggs, the severity of labor pain in the same dilatation was significantly lower in the intervention group than the control group. In our study, considering the nature of childbirth pain, the severity of labor pain was evaluated every 30 min using a pain ruler and this measure was conducted in the same dilatation. Rahmani et al. (31), in a study investigated the effect of dietary carbohydrate on the progress of labor and the rate of receiving analgesia in both groups showed no significant difference. In this regard, Scheepers et al. (32), showed that consumption of fluids containing increased epidural analgesia and fluid containing carbohydrate by carbohydrate intake group and entonox was more than the control group, although there was no statistically significant difference. It should be noted that in the study of Rahmani et al. (31) and Scheepers et al. (32), pain parameter using the appropriate tools to evaluate pain severity, such as VAS was not measured and was merely evaluated in group receiving analgesia, and in both studies, intake rate of analgesia showed no significant difference between the intervention and control groups.

Shabani et al. (28), showed in laboratory research on diabetic mice that palm syrup consumption increased pain threshold and tolerance; however, in a similar study by Zafari Zangeneh et al. (29), to evaluate the effect of diet containing palm on the pain threshold of rats, date consumption reduced pain threshold in daily usage, although this difference was not statistically significant.

\subsection{Conclusions}

In this study, the effect of date palm syrup on the reduction of labor pain and relieving the process of labor 


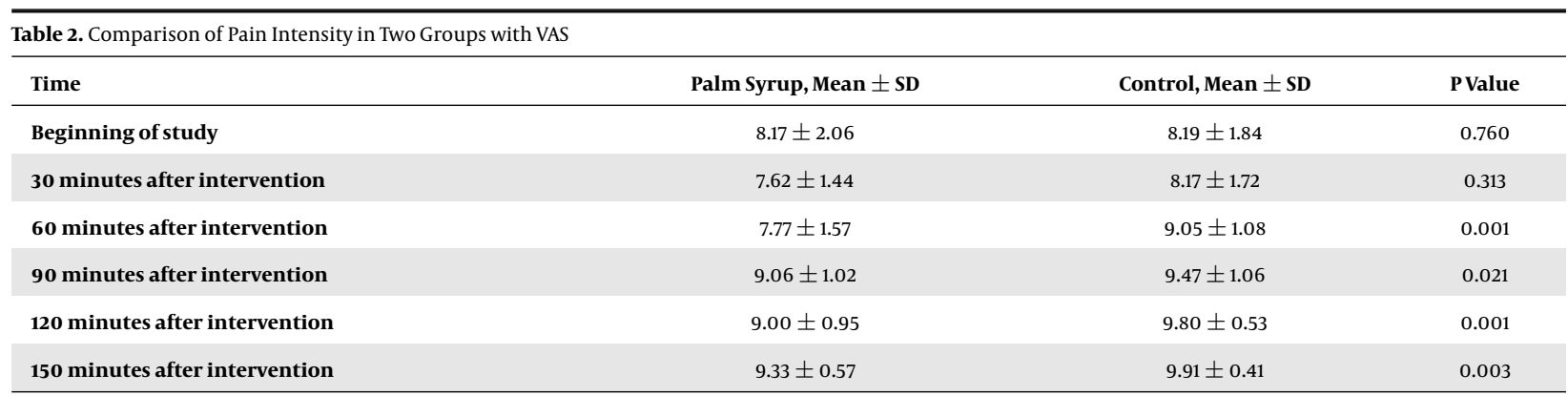

pain was evident and given that palm syrup after $60 \mathrm{~min}$ reduced pain, and up to $150 \mathrm{~min}$ after the intervention, pain had reduced significantly, it can be concluded that the starting impact occurred late in palm syrup usage, but it has a long relief effect. Therefore, it is suggested that due to the necessity of eating and drinking during labor which increases self-control of the mother and reduces stress in labor, date palm syrup should be consumed as the uncomplicated and analgesic nutrient to reduce energy and renew strength and reduce labor pain.

Finally, the pain score is subjective and several factors can effect on severity of pain so, this should be mentioned as a limitation of study.

\section{Acknowledgments}

This article is the outcome of the research project approved by Tehran University of Medical Sciences and Health Services under the Contract No. 93-02-28-25908 dated on 18 January 2015, and hereby, we would like to thank the concerned university. It is also our pleasure to acknowledge the efforts made by the hospital for their cooperation with us in collecting samples and would like to thank all the women who took part in this research.

\section{Footnotes}

Clinical Trial Registration: This project has been registered in the Center for International Registration of Clinical Trials with Code Number IRCT201405182172N16.

Conflict of Interests: Authors declare no conflict of interest.

Ethical Considerations: This study was approved by the Ethics Committee of Tehran University of Medical Sciences (TUMS) with code: 132686-9111373029.

Funding/Support: Tehran University of Medical of Sciences and Iran University of Medical of Sciences.

\section{References}

1. Cunningham FG, Leveno KJ, Bloom SL, Spong CY, Dashe JS, Hoffman BL, et al. Williams obstetrics. United States of America: McGraw-Hill Education; 2014.
2. Pillitteri A. Maternal and child health nursing: Care of the childbearing and childrearing family. Wolters Kluwer Health/Lippincott Williams \& Wilkins; 2010.

3. Wong CA. Advances in labor analgesia. Int J Womens Health. 2010;1:13954. [PubMed: 21072284]. [PubMed Central: PMC2971706].

4. Shnider SM, Abboud TK, Artal R, Henriksen EH, Stefani SJ, Levinson G. Maternal catecholamines decrease during labor after lumbar epidural anesthesia. Am J Obstet Gynecol. 1983;147(1):13-5. [PubMed: 6614080].

5. Lederman RP, Lederman E, Work B Jr, McCann DS. Anxiety and epinephrine in multiparous women in labor: Relationship to duration of labor and fetal heart rate pattern. Am J Obstet Gynecol. 1985;153(8):870-7. [PubMed: 4073158].

6. Garthus-Niegel S, Knoph C, von Soest T, Nielsen CS, Eberhard-Gran M. The role of labor pain and overall birth experience in the development of posttraumatic stress symptoms: A longitudinal cohort study. Birth. 2014;41(1):108-15. doi: 10.111//birt.12093. [PubMed: 24654643].

7. Lang AJ, Sorrell JT, Rodgers CS, Lebeck MM. Anxiety sensitivity as a predictor of labor pain. Eur J Pain. 2006;10(3):263-70. doi: 10.1016/j.ejpain.2005.05.001. [PubMed: 15987671].

8. Chaillet N, Belaid L, Crochetiere C, Roy L, Gagne GP, Moutquin JM, et al. Nonpharmacologic approaches for pain management during labor compared with usual care: A meta-analysis. Birth. 2014;41(2):12237. doi: 10.1111/birt.12103. [PubMed: 24761801].

9. Koyyalamudi V, Sidhu G, Cornett EM, Nguyen V, Labrie-Brown C, Fox CJ, et al. New labor pain treatment options. Curr Pain Headache Rep. 2016;20(2):11. doi: 10.1007/s11916-016-0543-2. [PubMed: 26780039].

10. Smith CA, Levett KM, Collins CT, Jones L. Manual healing methods including massage and reflexology for pain management in labour. Cochrane Db Syst Rev. 2011;(9). doi: 10.1002/14651858.CD009290.

11. Sanders RA, Lamb K. Non-pharmacological pain management strategies for labour: Maintaining a physiological outlook. Br J Midwifery. 2017;25(2):78-85. doi: 10.12968/bjom.2017.25.2.78.

12. de Oliveira DA, Ramos MG, Jordão V da RV, da Silva RAR, de Carvalho JBL, do Nascimento Costa MM. Use of non-pharmacological methods for providing pain relief during the natural childbirth: Integrative review. J Nurs. 2013;7(5):4161-70. doi: 10.5205/reuol.4134-32743-1SM-1.0705esp201309.

13. Taavoni S, Abdolahian S, Haghani H, Neysani L. Effect of birth ball usage on pain in the active phase of labor: A randomized controlled trial. J Midwifery Womens Health. 2011;56(2):137-40. doi: 10.1111/j.15422011.2010.00013.x. [PubMed: 21429078].

14. Smith CA, Levett KM, Collins CT, Jones L. Massage, reflexology and other manual methods for pain management in labour. Cochrane Database Syst Rev. 2012;(2). CD009290. doi: 10.1002/14651858.CD009290.pub2. [PubMed: 22336862].

15. Sharma S, Menia V, Bedi J, Dogra S. Labor analgesia: An unmet right of laboring women in India.J South Asian Fed Obstet Gynaecol. 2013;5:2632. doi: 10.5005/jp-journals-10006-1214. 
16. Tranmer JE, Hodnett ED, Hannah ME, Stevens BJ. The effect of unrestricted oral carbohydrate intake on labor progress. J Obstet Gynecol Neonatal Nurs. 2005;34(3):319-28. doi: 10.1177/0884217505276155. [PubMed: 15890830].

17. Ergol S, Eroglu K, Taskin L. The effect of oral fluid food support during labor on labor duration and perception of labor pains. Health Med. 2012;6(6):2093-9.

18. Chandrasekaran M, Bahkali AH. Valorization of date palm (Phoenix dactylifera) fruit processing by-products and wastes using bioprocess technology - Review. Saudi J Biol Sci. 2013;20(2):105-20. doi: 10.1016/j.sjbs.2012.12.004. [PubMed: 23961227]. [PubMed Central: PMC3730931].

19. Shah A, Marwat SK, Gohar F, Khan A, Bhatti KH, Amin M, et al. Ethnobotanical study of medicinal plants of semi-tribal area of Makerwal \& Gulla Khel (lying between Khyber Pakhtunkhwa and Punjab provinces), Pakistan. AM J Plant Sci. 2013;4(1):98. doi 10.4236/ajps.2013.41015.

20. Mirghazanfari SM. Assay of pharmacological features of phoenix Dactylifera in the view of traditional and modern medicine. Life Sci J. 2013;10(7):430-5.

21. Pujari RR, Vyawahare NS, Kagathara VG. Evaluation of antioxidant and neuroprotective effect of date palm (Phoenix dactylifera L.) against bilateral common carotid artery occlusion in rats. Indian J Exp Biol. 2011;49(8):627-33. [PubMed: 21870431].

22. Al-Taher AY. Possible anti-diarrhoeal effect of the date palm (Phoenix Dactylifera L) spathe aqueous extract in rats. Sci J King Faisal Uni. 2008;9(1):131-8.

23. Saafi EB, Louedi M, Elfeki A, Zakhama A, Najjar MF, Hammami M, et al. Protective effect of date palm fruit extract (Phoenix dactylifera L.) on dimethoate induced-oxidative stress in rat liver. Exp Toxicol Pathol. 2011;63(5):433-41. doi: 10.1016/j.etp.2010.03.002. [PubMed: 20359872].
24. Al-Daihan S, Bhat RS. Antibacterial activities of extracts of leaf, fruit, seed and bark of Phoenix dactylifera. Afr J Biotechnol. 2012;11(42):10021-5. doi: 10.5897|AJB11.4309.

25. Abedi A, Parviz M, Karimian SM, Sadeghipour Rodsari HR. Aphrodisiac activity of aqueous extract of Phoenix dactylifera pollen in male rats. Adv Sex Med. 2013;3(1):28. doi:10.4236/asm.2013.31006.

26. Khadem N, Sharaphy A, Latifnejad R, Hammod N, Ibrahimzadeh S. Comparing the efficacy of dates and oxytocin in the management of postpartum hemorrhage. Shiraz E-Med J. 2007;8(2):64-71.

27. Kordi M, Salek Nasiri N, Safarian M, Esmaiili H, Shadjo K. [The effect of oral honey- date syrup intake during labor on labor progress of nulliparous women]. Iran J Obest Gynecol Infertility. 2010;13(2):23-30. Persian. doi: 10.22038/IJOGI.2010.5861.

28. Shabani M, Zangiabadi N, Asadi-Shekaari M. Evidence for positive effects of date extract that attenuates thermal hyperalgesia in a diabetic rat model of neuropathic pain. Neurosci Med. 2013;4(1):16. doi: 10.4236/nm.2013.41003.

29. Zafari Zangeneh F, Moezi L, Zargar AA. [The effect of palm date, fig and olive fruits regimen on weight, pain threshold and memory in mice]. Iran J Med Aromatic Plants. 2009;25(2):149-58. Persian.

30. Hekmatzadeh SF, Mirmolaei ST, Hoseini N. [The effect of boiled dill (Anethum graveolens) seeds on the long active phase and labor pain intensity]. Armaghane danesh. 2012;17(1):50-9. Persian.

31. Rahmani R, Khakbazan Z, Yavari P, Granmayeh M, Yavari L. Effect of oral carbohydrate intake on labor progress: Randomized controlled trial. Iran J Public Health. 2012;41(11):59-66. [PubMed: 23304677]. [PubMed Central: PMC3521887].

32. Scheepers HC, Thans MC, de Jong PA, Essed GG, Le Cessie S, Kanhai $\mathrm{HH}$. A double-blind, randomised, placebo controlled study on the influence of carbohydrate solution intake during labour. BJOG. 2002;109(2):178-81. [PubMed: 11911101]. 